Esta obra forma parte del acervo de la Biblioteca Jurídica Virtual del Instituto de Investigaciones Jurídicas de la UNAM

www.juridicas.unam.mx

\title{
CONSTITUCIÓN Y "CLÁUSULAS ECONÓMICAS \\ Y SOCIALES". ALGUNAS NOTAS ACERCA \\ DE LA OPERATIVIDAD DE LAS NORMAS \\ CONSTITUCIONALES*
}

\section{CONSTITUTION AND "ECONOMIC AND SOCIAL CLAUSES". SOME NOTES ABOUT THE OPERATIVENESS OF CONSTITUTIONAL NORMS}

\author{
Francisco ZÚÑIGA URBINA
}

RESUMEN: El artículo sostiene que las "cláusulas económicas y sociales" de la Constitución deben ser analizadas desde una teoría de las normas iusfundamentales que dé cuenta de su tipo, estructura normativa y real eficacia u operatividad, sometiendo a crítica aquella doctrina de cuño neoliberal y neoconservador que niega eficacia normativa a las cláusulas y en especial a los derechos sociales.

Palabras clave: Constitución económica, Estado social, normas constitucionales.
ABSTRACT: This article argues that the "economics and social clauses" of the Constitution to have analyzes since an theory of the constitutional norms that to gather type, normative structure and real efficacy, subject critic the doctrine of inspiration liberal and conservative negative of the normative efficacy of the clauses and specially the social rights.

Descriptors: Economic Constitution, Welfare State, Constitutional Norms.

* Ponencia presentada en las Jornadas Argentino, Chileno, Peruanas de Derecho Constitucional en el tema "Garantías constitucionales económico-sociales", realizadas del 6 al 9 de mayo de 2009 en Viña del Mar, Chile. 


\section{PRESENTACiÓN}

El propósito de este trabajo es abordar las denominadas "cláusulas económicas y sociales" de la Constitución, su compleja composición y asunción de forma constitucional mediante normas constitucionales, de heterogénea identidad y de una estructura normativa interna que va de la mano con el carácter "especial" o "peculiar" que posee la Constitución como norma; y a partir de este análisis avanzar acerca del grado de operatividad de estas normas que formulan valores, principios, directrices, fines del poder político estatal, además de consagrar derechos económicos, sociales y culturales. Luego afirmar que la Constitución es un sistema normativo que posee "fuerza normativa" (obligatoria y vinculante) por revestir tal instrumento del carácter de norma y no un mero carácter declarativo u orientativo, que requiere de una necesaria precisión de sus términos para no vernos aquejados de la patología del "fetichismo constitucional", y no existe mejor pretexto para abordar esta cuestión que la zona límite en que se sitúan las "cláusulas económicas y sociales".

Estas "cláusulas económicas y sociales" son fruto de un estadio de evolución del Estado moderno y de sus Constituciones, e insertas en revoluciones como la mexicana de 1910, rusa de octubre de 1917 y alemana de 1919, aquilatando en las Constituciones y en el constitucionalismo de entreguerras de la mano del constitucionalismo social y de la crisis del orden político liberal y del capitalismo temprano, época descrita formidablemente por Mirkine Guetzevitch. ${ }^{1}$

Los ciclos constitucionales de posguerra, en especial las transiciones desde las duraderas dictaduras europeo-mediterráneas a la democracia (Portugal, Grecia y España) en la década de 1970 y las transiciones desde las también duraderas autocracias comunistas de Europa central y oriental a partir de 1989, dan cuenta de un reforzamiento en la recepción de las "cláusulas económicas y sociales" en la Constitución, y la consolidación de una Constitución económica y de una Constitución social en

1 Una síntesis de las nuevas tendencias constitucionales modernas en Mirkine Guétzevitch, Boris, "Estudio preliminar", Las nuevas Constituciones del mundo, Madrid, Editorial España, 1931, pp. 7-57. Del mismo autor, Modernas tendencias del derecho constitucional, Madrid, Reus, 1934, pp. 3 y 4. 
las Constituciones, con un cuño ideológico plural o abierto, receptor del constitucionalismo liberal, democrático y en especial social. ${ }^{2}$

En América Latina, las transiciones a la democracia de la década de 1980 dan cuenta también de un constitucionalismo nuevo, con influencias europeas en especial española-portuguesa en muchas instituciones, un constitucionalismo maximalista y cuya expresión más notoria hoy es el constitucionalismo dominante en Venezuela, Ecuador y Bolivia. Se observa respecto de estos procesos constitucionales en algunos sentidos revolucionarios una profunda incomprensión desde la ciencia política y del derecho constitucional, derivado del supuesto pecado o error de la "grafomanía constitucional" (Sartori), reflejo de un máximo nominalismo constitucional y divorcio entre normatividad y facticidad, Constitución y realidad político, social y económica. ${ }^{3}$

La Constitución de Chile se encuentra al margen de este proceso del constitucionalismo latinoamericano, que arranca de la restauración de sistemas democráticos, en la medida que su transición política democrática fue una transición pactada, teniendo que aceptar una Constitución heredada del régimen autoritario, con un cuño ideológico autoritario en lo político, neoliberal en lo económico y un cierto influjo corporativista o fascistizado en lo social. En suma, 1973 es una revolución jurídicamente hablando y el nuevo orden que cristaliza en la Constitución de 1980, es fiel reflejo de los intereses e ideologías de clase que se imponen por la fuerza el 11 de septiembre de 1973, y asumen la presentación de reformas fiscales y modernizaciones. De este modo, la transición estuvo marcada por el signo de las reformas constitucionales orientadas a suprimir de la parte orgánica o "estatuto del poder" los "enclaves autoritarios" de-

2 Sobre el constitucionalismo social y el término "cláusulas económicas y sociales" es de consulta obligada Vanossi, Jorge R., El Estado de derecho en el constitucionalismo social, Buenos Aires, Eudeba, 1987, pp. 355-392. Sobre los ciclos constitucionales dos obras muy importantes, Biscaretti di Ruffia, Paolo, Introducción al derecho constitucional comparado, trad. de Héctor Fix-Zamudio, México, Fondo de Cultura Económica, 1996, 716 pp.; y De Vergottini, Giuseppe, Derecho constitucional comparado, trad. e introd. de Pablo Lucas Verdú, 2a. ed., Madrid, Espasa-Calpe, 1985, con una nueva edición con traducción de la 6a. edición italiana, México, UNAM, Instituto de Investigaciones Jurídicas, 2004, 724 pp., y del mismo autor, Las transiciones constitucionales: desarrollo y crisis del constitucionalismo a finales del siglo $X X$, trad. de Santiago Perea Latorre, Bogotá, Universidad Externado de Colombia, 2002, 253 pp.

3 Consultar a Sartori, Giovanni, Ingeniería constitucional comparada, trad. de Roberto Reyes Mazzoni, México, Fondo de Cultura Económica, 1996. 
jados por el régimen y eventualmente transformar a alguno de éstos en instituciones contramayoritarias. Este proceso se cierra malamente con la reforma constitucional de 2005, promulgada mediante la Ley 20.050, y desde esta perspectiva del "estatuto del poder" la Constitución vigente es en gran medida "nueva Constitución", aunque desde la perspectiva dogmática (Constitución económica y social) la Constitución vigente es "vieja Constitución". Ello justifica intentar abrir hoy una "operación constituyente", sea un proceso de reformas de "segunda generación" o de "Nueva Constitución del Bicentenario".

Sobra señalar que en Chile las "cláusulas económicas y sociales" adolecen de una debilidad estructural al igual que los derechos económicos sociales y culturales en el "sistema de derechos", ligados a la fórmula del Estado subsidiario o mínimo. Luego, la constitucionalización de "cláusulas económicas y sociales" que abran la forma jurídico-política de Estado, y las relaciones de éste con la economía y sociedad civil, no ha sido posible en las reformas de primera generación (1989-2005), a pesar de haberse discutido la ampliación y el reforzamiento de derechos sociales como el derecho a la educación, la protección institucional de derechos a través de una defensoría del pueblo o de las personas y recepción de la fórmula del Estado social.

Este trabajo está condenado a tropezar con una dogmática constitucional tradicional en Chile dominada por un sesgo ideológico neoliberal y neoconservador, que repugna de la fórmula del Estado social y democrático de derecho, de las "cláusulas económicas y sociales" de una Constitución económica y social abierta en lo ideológico a los aportes del constitucionalismo democrático y social. Ahora bien, la repugnancia hacia estas formas constitucionales se asila en el arsenal teórico constitucional tradicional o clásico y adopta formulaciones archirrepetidas, yerros que de repetidos parecen verdad, a saber:

a) La defensa de Constituciones breves, como la Constitución de Filadelfia de 1987, las que resultarían ideales al limitarse a fijar el instrumento de gobierno en los términos del artículo 16 de la Declaración francesa de 1789.

b) En cambio, las Constituciones desarrolladas son demostración de un acusado nominalismo constitucional, o de una "grafomanía" constitucional expresiva del divorcio entre el texto y la realidad. 
c) Las "cláusulas económicas y sociales" de una Constitución: normas de principio, derechos sociales, derechos de minorías, pueblos indígenas, multiculturalismo, amparo de derechos colectivos e intereses difusos, entre otros, son "normas programáticas" supeditadas a la fiscalidad estatal, verdaderas "promesas" o "aspiraciones" irrealizables de "justicia social" y por ende perniciosas, porque debilitan la "majestad" o supremacía formal-material de la Constitución. ${ }^{4}$

d) Los derechos económicos, sociales y culturales no son derechos subjetivos, sino que carecen de eficacia normativa y carecen de justiciabilidad, más aún su justiciabilidad es perniciosa para el sistema de derechos, el sistema democrático y la gobernabilidad.

e) Las "cláusulas económicas y sociales" pertenecen al campo de la política y de las políticas públicas, y por ende son resortes del gobierno y su administración, determinados por orientaciones programáticas o ideológicas imperantes de tiempo en tiempo.

En el fondo, la dogmática constitucional más tradicional devalúa con fines ideológicos estas "cláusulas económicas y sociales", desconociendo que son normas iusfundamentales y, por ende, parte del derecho de la Constitución, dotadas de supremacía, valor y eficacia normativa, y objeto de hermenéutica constitucional. En cambio, poniendo en evidencia la "trampa ideológica" usada, la misma dogmática tradicional no devalúa el Estado mínimo o subsidiario y los derechos civiles de contenido patrimonial de la Constitución.

En este lugar, simplemente queremos recoger una modesta reflexión acerca de las normas iusfundamentales, tipo de normas y su estructura normativa, para dar cuenta así de la real eficacia normativa u operatividad de sus reglas de competencia, y de este modo desvelar los tópicos o lugares comunes acerca del Estado social y de los derechos sociales; reconociendo al mismo tiempo que tales fórmulas deben ser incorporadas en una perspectiva de Constitutione ferenda a la Constitución vigente. Asimismo, se hace necesario a la luz de la Constitución económica abierta a los aportes del constitucionalismo social y democrático "releer" el derecho común preconstitucional e imponer un sello expansivo-progresivo al desarrollo infraconstitucional de las "cláusulas económicas y sociales", en especial al desarrollo legislativo, y en ese campo es el lugar en

4 Zippelius, Reinhold, Teoría general del Estado, trad. de Héctor Fix-Zamudio, México, UNAM, 1985, pp. 357 y 358. 
que se reintroduce necesariamente la política en la fijación de las herramientas de protección de derechos fundamentales.

Nuevamente se impone la cortesía de hacer explícito el enfoque teórico-metodológico positivista del cual somos tributarios, lejano del positivismo ideológico, que no renuncia a la crítica jurídica o interna y a la crítica política o externa, y en razón de ello sostenemos que la democracia constitucional está incompleta en nuestro ordenamiento sin "cláusulas económicas y sociales" dotadas de garantías primarias de los derechos sociales y técnicas que obliguen a los poderes públicos a su materialización. En efecto, los derechos fundamentales en general y los derechos sociales en particular tienen funciones no circunscritas al limitar el poder estatal, sino a su legitimidad y crítica, por lo que es posible como lo sostiene Ferrajoli identificar el grado de legitimidad del ordenamiento en una democracia constitucional con el grado de eficacia de las garantías de sus derechos. ${ }^{5}$

\section{CONSTITUCIÓN Y NORMAS CONSTITUCIONALES}

El constitucionalismo moderno en sus diversas tradiciones o vertientes (liberal, democrática y social) admite como paradigma dominante un concepto normativo de Constitución distante del paradigma decimonónico de un concepto político, retomando así la tradición de los monarcómacos. Conforme a este concepto normativo, la Constitución es la una ley suprema u orden jurídico fundamental, fruto de la autodeterminación política del pueblo y recipiente de compromisos, que aquilatan en un techo ideológico abierto o plural, todo lo que es determinante para los fines y estructura normativa de la carta política. Asimismo, la Constitución cumple ciertas funciones básicas y tiene un contenido usual: el estatuto del poder político estatal y el estatuto o carta de derechos, deberes y garantías constitucionales. ${ }^{6}$

5 Ferrajoli, Luigi et al., La teoría del derecho en el paradigma constitucional, Madrid, Fundación Coloquio Jurídico Europeo, 2008, pp. 112-114. También la magna obra de Ferrajoli, L., Principia iuris. Teoria del diritto e della democrazia, Roma-Bari, Gius, Laterza \& Figli, 2007, 3 vol., vol. 2, pp. 392-418.

6 Sobre la Constitución y el constitucionalismo histórico, una sinopsis aparece en Fioravanti, Mauricio, Constitución. De la antigüedad hasta nuestros dias, Madrid, Trotta, 2001 y Grimm, Dieter, Constitucionalismo y derechos fundamentales, Madrid, Trotta, 2006, pp. 107-153. Sobre la Constitución formal-material, un texto obligado de De Otto 
La Constitución, entendida como ley suprema, tiene dos dimensiones: es la norma básica en la medida que determina la producción válida de normas de todo el ordenamiento jurídico (Kelsen), y es un subsistema de normas iusfundamentales que operan como reglas de competencia (Ross), un "derecho de la Constitución" compuesto de dos partes: en el lenguaje del criticado dualismo tradicional, de un derecho objetivo y de un derecho subjetivo. De este modo, los principios de constitucionalidad: supremacía formal-material, valor normativo y eficacia normativa, no son sino consecuencia de su autoafirmación de supraordenación jerárquica de un sistema cerrado y completo de normas. ${ }^{7}$

Así, las normas iusfundamentales de conducta (dirigidas a los sujetos) y de organización (dirigidas al Estado), en el añoso lenguaje de Posada de la parte "dogmática" y de la parte "orgánica" de la Constitución, están enderezadas a tener eficacia normativa, directa o indirecta, positiva o negativa, con o sin desarrollo infraconstitucional, y vinculan a todos los poderes públicos y a todas las personas o sujetos; especialmente vinculan a los tribunales de justicia en la tutela del derecho, exigen de un custodio jurisdiccional supremo y obligan a una "interpretación conforme" a la Constitución.

La eficacia normativa de la Constitución o más precisamente de sus normas es eficacia directa cuando sin desarrollo infraconstitucional sus reglas pueden ser aplicadas por los destinatarios de estas normas o los jueces, y es eficacia indirecta cuando sus reglas están dirigidas a los poderes normativos y en especial al legislador.

Sin embargo, la Constitución o mejor dicho sus normas iufundamentales tienen eficacia positiva o negativa, pues son básicamente reglas de competencia, lo que hace equívoco el distingo de filiación neoiusnaturalista y en boga entre reglas y principios. En el fondo, las normas constitucionales asumen el carácter de normas o reglas de competencia en el

Pardo, Ignacio, Derecho constitucional. Sistema de fuentes, Barcelona, Ariel, 1985, pp. 28-56; y del mismo autor, Lecciones de derecho constitucional. Introducción, Oviedo, Guiastur, 1980, pp. 79-107.

7 Consultar a Kelsen, Hans, Teoría pura del derecho, trad. de Roberto J. Vernengo, 7a. ed., México, Porrúa-UNAM, 1993, pp. 232-235; y del mismo autor, Teoría general del derecho y del Estado, trad. de Eduardo García Máynez, 3a. ed., México, UNAM, 1969, pp. 146-152. Ross, Alf, Sobre el derecho y la justicia, trad. de Genaro Carrió, Buenos Aires, Eudeba, 1963, pp. 76-81 y "On the concepts 'State' and 'State organs' in Constitutional Law”, Scandinavian Studies in law, Estocolmo, núm. 5, 1961, pp. 11-129. 
sentido que establecen, habilitan, limitan u orientan el poder estatal; de suerte que las normas de conducta son reglas de competencia negativa o prohibitiva, puesto que fijan límites a la actividad del poder estatal, como ocurre con las normas relativas a derechos que delimitan un ámbito de personalidad (subjetividad y autonomía); y las normas de organización son reglas de competencia positiva o afirmativa, en la medida que son constitutivas de órganos, atributivas de competencia y procedimientos, y determinantes en la fijación de relaciones interinstitucionales, pudiendo además estas normas fijar directrices u orientaciones al poder del Estado o establecer pautas para la hermenéutica de la Constitución o de sus partes componentes, estableciendo programaciones, objetivos, medios y fines; como ocurre en nuestro país al concebir la Constitución a la administración del Estado como una administración para el desarrollo.

Estas normas iusfundamentales, sean permanentes o transitorias, tienen una estructura normativa interna abigarrada, heterogénea y con notas características basales a las que nos referiremos en el apartado siguiente y que hacen peculiar a la Constitución.

De esta estructura normativa interna, y compatible con la distinción básica entre normas de conducta y normas de organización, es posible identificar, siguiendo los aportes de Huber, Scheuner y Rubio Llorente, las normas iusfundamentales siguientes: normas declarativas y principios fundamentales (normas de principio), normas de reconocimiento de derechos, normas de reconocimiento de garantías (institucionales, normativas y jurisdiccionales o procesales), habilitaciones, mandatos, prohibiciones y directrices a los poderes públicos, normas sobre producción de normas (incluidas las normas de reforma constitucional), normas de renvío, y normas orgánicas (sobre organización y funcionamiento de órganos del Estado, normas de procedimiento, normas atributivas de competencias). Otro autor germano K. Stern nos propone como clasificación de normas constitucionales, la siguiente: normas de competencia, normas de creación de órganos del Estado, normas de procedimiento, normas de reforma o revisión constitucional, disposiciones normativas, normas sobre derechos fundamentales, normas sobre garantías, normas sobre estructura y fines del Estado, normas con mandatos constitucionales, normas jurídi- 
co-materiales y normas jurídico organizatorias. ${ }^{8}$ Sobra señalar que desde la heterogeneidad reseñada las normas iusfundamentales pueden ser encuadradas tipológicamente en más de una de estas categorías taxonómicas.

La concepción dominante de la Constitución como ley suprema, y su autorreconocimiento de valor y eficacia normativa, permite sostener que ésta es el tronco a partir del cual todas las ramas del derecho nacen, y proyecta sus efectos duraderamente sobre tales ramas, y además es en sí como subsistema normativo un derecho que bajo determinadas condiciones es directamente aplicable. Lo anterior conlleva en la teoría constitucional contemporánea a un cierto exceso bajo la etiqueta de "fuerza normativa" de la Constitución que hace de ésta un demiurgo normativo, deus ex machina o totum normativo; que deviene en una verdadera patología que denominamos "fetichismo constitucional", la que hemos criticado sistemáticamente en diversos trabajos apelando a un sinceramiento y realismo mínimos.

Esta patología "fetichista" de raíz iusnaturalista tan extendida en la teoría constitucional y sus autores contemporáneos, por un lado ha "sacralizado" política y jurídicamente la Constitución declarándola suprema, inviolable y normativa y, por otro, a la hora de la verdad, enfrentados con el "barro del ídolo que ellos mismos han creado, se ven obligados a acudir a fórmulas incoherentes con sus posiciones dogmáticas" (Nieto). En nuestro caso el "fetichismo constitucional" sacraliza una Constitución vigente "nueva-vieja", de origen otorgado autoritario y neoliberal; dando abrigo dogmático, teórico y práctico a la custodia de la Constitución por el Tribunal Constitucional, usando como regla hermenéutica prevalente o al menos de frecuente uso la "historia fidedigna", sea en su variante literalista o intencionalista. En el fondo, el "fetichismo constitucional" confunde la normatividad (valor y eficacia normativa) con la aplicación directa u "operatividad" de normas constitucionales y aquejadas de panjudicialismo, con su amplio control jurisdiccional.

8 Consultar recopilación de trabajos de Rubio Llorente, Francisco, La forma del poder, Madrid, Centro de Estudios Constitucionales, 1993, pp. 88 y 89. También el libro de Requejo P., José Luis, Sistemas normativos, Constitución y ordenamiento, Madrid, McGraw-Hill, 1995. De Stern, Klaus, Derecho del Estado de la República Federal Alemana, trad. de J. Pérez Royo y P. Cruz Villalón, Madrid, Centro de Estudios Constitucionales, 1987, pp. 265-279. 
Nuestro propósito en este lugar es muy modesto. Consiste en dar cuenta sumariamente de una estructura normativa interna y fines de la Constitución, que hacen de ésta un "marco abierto" o "abanico de posibilidades", en razón de su extensión, polivalencia y diseño normativo iusfundamental, que determina los alcances del desarrollo normativo infraconstitucional, de la hermenéutica constitucional y de cuándo debe entrar a tallar la reforma constitucional con sus órganos y procedimientos prestablecidos o "poder constituyente derivado". 9

\section{CONSTITUCIÓN Y ESTRUCTURA NORMATIVA}

Constituye un tópico afirmar que el derecho constitucional es la juridificación de la política, expresión de la racionalización del poder propia del Estado moderno y su forma jurídico-política es el Estado de derecho, y su síntesis se expone con la forma política estatal: republicano-democrática, es la denominada "democracia constitucional" o "Estado constitucional". A partir de este tópico se hace necesario establecer en la Constitución un techo ideológico, usualmente abierto o plural, y funciones precisas por una parte, y una composición de normas constitucionales que exige una taxonomía adecuada y una estructura normativa interna por otra parte, todo lo cual permite concebir a la carta política como "ley peculiar" o "naturaleza especial" (Linares Quintana), y debemos añadir distinta a la legislación.

Luego, para nuestro propósito es necesario recoger algunas ideas acerca de la estructura normativa interna iusfundamental, y cómo esta estructura determina su desarrollo infraconstitucional y su hermenéutica. En este sentido nos recuerda Martínez Sospedra:

La afirmación de la Constitución como ley peculiar se debe tanto a su especial significación política como a su no menos especial posición en el ordenamiento, y ello tiene reflejo tanto en las técnicas de redacción de la Constitución misma como en las funciones que en el sistema jurídico la ley fundamental cumple. Finalmente tiene un papel decisivo a la hora de afrontar

9 Sobre la interpretación y sus reglas consultar a Wroblewski, J., Constitución y teoría general de la interpretación jurídica, Madrid, Tecnos, 1985 y Alonso, E., La interpretación de la Constitución, Madrid, Centro de Estudios Constitucionales, 1984. En el continente, un texto clásico es Linares Quintana, Segundo V., Reglas para la interpretación constitucional según la doctrina y jurisprudencia, Buenos Aires, Plus Ultra, 1987. 
una cuestión capital en un Estado como el nuestro en el que la Constitución es norma de aplicación directa y existe un sistema organizado y eficiente de justicia constitucional, a saber, el problema de la interpretación de la Constitución misma.

En suma, observa Hesse, las normas iusfundamentales son peculiares por su rango o posición jerárquica, clase de sus reglas, condiciones de su validez y capacidad para imponerse a la realidad social; lo que obliga a armonizar supremacía y vinculación a la Constitución con su carácter abierto, indeterminación y amplitud de sus normas, en su lenguaje y estructura; permitiendo concluir lógicamente que estas normas "no son completas ni perfectas". ${ }^{10}$

Por otra parte resulta tradicional para los operadores jurídicos formados por largo tiempo en una cultura legiscentrista el empleo de reglas y criterios hermenéuticos consolidados, v. gr. las reglas de Savigny, esenciales para la interpretación y aplicación de la legislación, en torno a las cuales se han diseñado las principales técnicas de desarrollo e interpretación. Ello contrasta con la hermenéutica constitucional en que la "naturaleza especial" (Linares Quintana) o de ley peculiar que posee el derecho de la Constitución, determina reglas hermenéuticas específicas. La ley y la legislación tienen una finalidad distinta de la ley constitucional y su estructura o diseño difiere notablemente del de ésta.

La ley y la legislación están diseñadas, nos advierte Martínez Sospedra:

1. Para el desarrollo y aplicación de políticas sectoriales y concretas. La ley ordinaria es, normalmente, una ley dirigida a ordenar un sector concreto de la sociedad, y a ordenar dicho sector de la realidad social en razón de una política determinada, escogida por el legislador de entre una pluralidad de políticas

10 Martínez Sospedra, Manuel, Estado y Constitución. Una introducción, Valencia, Fundación Universitaria San Pablo CEU, 1991, p. 257, y Derecho constitucional español, Valencia, Fundación Universitaria San Pablo CEU, 1995, pp. 68-72. Del eminente jurista germano Hesse, Konrad, se consultó su trabajo introductorio en la obra colectiva Manual de derecho constitucional, Madrid, IVAP-Marcial Pons, 1996, y Escritos de derecho constitucional, trad. e introd. de P. Cruz Villalón, Madrid, Centro de Estudios Constitucionales, 1983, p. 17. También del administrativista español Nieto, Alejandro, "Peculiaridades jurídicas de la norma constitucional", Revista de Administración Pública, vol. 1, núm. 100/02, 1983; Estudios de derecho y ciencia de la administración, Madrid, Centro de Estudios Políticos y Constitucionales, 2001, pp. 85-123. 
posibles. Por muy amplio que sea el campo normativo de la ley ordinaria éste es siempre sectorial y expresa, por ello, una ordenación inspirada en políticas asimismo sectoriales.

2. Proporcionar, en la medida de lo posible, una solución legal única a cada problema. En tanto que instrumento de una política concreta la ley ordinaria está diseñada para dar en cada caso una solución legal única o una gama muy reducida de soluciones legales estrechamente ligadas o emparentadas entre sí. En la medida de lo posible el ideal de la ley ordinaria es la univocidad, obtener el resultado de un significado único, preciso, de cada uno de sus enunciados, siendo en este sentido el caso extremo el de las normas penales. Ideal de univocidad que es consecuencia del propósito político unitario, y del carácter sectorial de la ley, y que explica la utilización intensiva por el legislador de la terminología técnico-jurídica, dado que ésta está diseñada, precisamente, para reducir la equivocidad mediante la precisión conceptual y terminológica.

3. La huida del lenguaje ordinario. La consecuencia necesaria de este planteamiento es la búsqueda de un lenguaje peculiar para expresar y comunicar las normas, de donde una tendencia muy marcada a la especialización terminológica en las diversas ramas del saber jurídico. La exigencia del lenguaje técnico-jurídico propio de cada rama del derecho, que vienen referidas a grandes áreas o sectores de la realidad social, así como la afirmación de la autonomía que cada una de aquellas reclama para la fijación de sus propios conceptos entrañan el progresivo abandono del lenguaje común como instrumento para expresar las normas a favor de la terminología propia de cada rama del derecho. Lo que, dicho sea de paso, aleja de la norma al ciudadano común y dota de una no despreciable influencia política a esa suerte de opinión pública de los juristas que llamamos "la doctrina".

4. Una duración limitada. El propósito ordenador directo de la ley ordinaria conduce a la limitación de la vida de la misma. En una sociedad en rápido cambio de las condiciones económicas, técnicas, sociales, etcétera, una normativa que busca ordenar un sector de la realidad social para orientarlo según opción política concreta está fuertemente sujeta al condicionante de la cláusula rebus sic stantibus. La ley ordinaria nace con vocación de permanencia, pero su fundamental propósito ordenador de un sector concreto en una realidad social en rápido cambio, surte una fuerte permanencia: sólo es posible en aquellos sectores de la realidad en los que los cambios son muy lentos o inexistentes, en los que las inercias son extremadamente fuertes, en la medida en que tales sectores tienen una importancia reducida - $\mathrm{y}$ aun menguante - en la sociedad moderna, lo que caracteriza a la mayoría de aquéllas es, ciertamente, su escasa estabilidad. 
5. La importancia de la solución más legal. Es el objetivo de la ley ordinaria. En tanto que instrumento de una política sectorial concreta de ordenación la efectividad de la norma ordinaria exige la imposición de los operadores jurídicos una estrecha vinculación por la ley. Por ello administrar la ley es ejecutar la ley. La ley no se limita a habilitar a los poderes públicos y a los particulares para desarrollar actividades de aplicación que, de alguna manera, son discrecionalmente escogidos por éstos, la ley impone a sus administradores no un marco o unas orientaciones genéricas, sino unas prescripciones detalladas que conducen a una gama muy reducida de opciones entre las que el administrador tiene que optar, en el mejor de los casos, y, si es posible, imponer una solución única. ${ }^{11}$

En cambio, sobra decirlo, la norma constitucional se halla muy alejada del diseño referido, obedece a finalidades distintas, tiene un campo de aplicación diferente, se redacta mediante técnicas propias, tiene una amplia vocación de permanencia y no busca tanto prescribir políticas como limitar las opciones que los actores políticos pueden escoger legítimamente, usualmente con techo ideológico abierto. Martínez Sospedra nos dice:

La ley constitucional difiere de la ley ordinaria por una razón fundamental: el objeto propio de la ley constitucional no es un sector de las relaciones sociales, sino su totalidad; la finalidad de la ley constitucional no es establecer ordenaciones con vistas a la imposición de políticas concretas, sino establecer un marco general de relaciones jurídicas que, determinando los modos, condiciones y formas de producción de reglas de derecho, permita el desarrollo en normas concretas-ordinarias de políticas diferentes.

Usando un símil singularmente adaptado, el objeto propio de la Constitución es establecer "las reglas del juego político y no diseñar las singulares estrategias y tácticas del juego mismo", ya que la Constitución condensa derecho y política en un orden fundamental o marco, lo que la aleja de poseer un "carácter sacro" (Nieto), más bien su carácter es profano.

De lo expuesto podemos enunciar las características basales del diseño o estructura normativa de la Constitución, que como hemos dicho es esencial para determinar el alcance de su desarrollo infraconstitucional y

11 Martínez Sospedra, Manuel, op. cit., nota anterior, pp. 258-260. 
de su hermenéutica. De estas características basales subrayamos con Martínez Sospedra las siguientes:

1. La Constitución es un marco general. No hace falta recurrir a la noción clásica de la Constitución como actualización del contrato social para convenir que la función propia de la ley fundamental es establecer la ordenación general del Estado, esto es establecer aquellas reglas jurídicas que determinan quién está legitimado para ejercer el poder público, en qué condiciones y con qué límites puede el mismo ser legítimamente ejercido y qué finalidades generales, en cuanto constituyen un auténtico proyecto político de Estado, deben ser perseguidas mediante las diferentes políticas concretas cobijables bajo la Constitución misma. Si la Constitución es la norma de cabecera del ordenamiento, en la que diversas ramas del mismo entran sus respectivas "têtes de chapitre", se debe precisamente a ese hecho.

2. La Constitución es norma de vocación pluralista. Por su propia naturaleza la Constitución no es norma llamada a prescribir políticas concretas, antes bien es norma dirigida a establecer la estructura general del ordenamiento y a facilitar, de este modo, la definición, la adopción, el desarrollo y actuación de una pluralidad de políticas concretas. No hay una sola política constitucional, la Constitución ampara una diversidad de políticas posibles y se limita a excluir, de la totalidad de las políticas adoptables, tan sólo aquellas que no son compatibles con la ordenación general de la sociedad que la misma prescribe, con el proyecto de Estado que la misma incorpora. Nos encontramos aquí en las antípodas de la ley ordinaria. En términos generales nunca hay una solución única, una sola solución constitucional a los problemas que se presenten, siempre hay diversas políticas legítimas sobre sectores concretos dentro del marco constitucional, expresión que difícilmente puede ser más ilustrativa.

3. La Constitución no contiene, como regla general, normas inspiradas en el propósito de lograr una solución única. La consecuencia resulta obvia tras lo dicho. La apertura a una pluralidad de políticas (sobre cualquiera de las materias no contempladas por la Constitución, e incluso sobre aquellas que la Constitución de algún modo contempla), implica la limitación de la norma constitucional a la fijación de normas generales de orientación que pueden ser concretadas en orientaciones políticas diversas y, por tanto, en normas ordinarias también diversas. De ahí que las técnicas de redacción de la Constitución sean diversas a las de la ley ordinaria y que, en consecuencia, la interpretación constitucional tenga exigencias diferenciadas.

4. La Constitución tiene vocación de perpetuidad. Lo que no es más que una consecuencia de su naturaleza de ordenación general, de norma de cabe- 
cera y marco de las demás normas. Ello exige, asimismo, técnicas redaccionales y de interpretación peculiares, y es la causa final de determinadas instituciones, destinadas a garantizar la continuidad del ordenamiento general mediante su adaptación. Esa es la razón de ser la jurisprudencia constitucional o de los sistemas de reforma constitucional.

5. Legislar no es ejecutar la Constitución. Por tanto la relación entre la Constitución y las normas ordinarias no es homologable a la que pueda existir entre la ley ordinaria y las normas subordinadas a la misma. No existiendo una única solución constitucional, una sola ordenación de materia concreta que complete y agote las posibilidades constitucionales, más bien al contrario, al existir siempre una pluralidad de opciones constitucionalmente legítimas la opción por un determinado tipo de ordenación legal ordinaria entra dentro de la esfera de acción legítima del legislador, del Parlamento, siempre que no entre en contradicción con el orden vinculante de convivencia constitucionalmente fijado. ${ }^{12}$

Establecida esta cuestión: la Constitución - porque busca finalidades diferentes a la ley y a la legislación, y posee un diseño o estructura normativa distinta - no es susceptible de ser redactada de acuerdo con las mismas técnicas que aquélla, ni puede ser interpretada del mismo modo.

La Constitución como "orden fundamental", "marco general" o "abanico de posibilidades", exige el recurso a técnicas peculiares, las normas de cabecera o "têtes de chapitre" a que se refería Pellegrino Rossi en los albores de la disciplina a mediados del siglo XIX, las que deben satisfacer exigencias que no se hallan presentes en la ley y legislación. En este orden de ideas, son cuatro las técnicas más usuales y extendidas en la conformación de las normas constitucionales: el uso abundante de la normación incompleta, la frecuencia del recurso a conceptos jurídicos indeterminados, la mayor relevancia del lenguaje ordinario y la relativa rareza del recurso al lenguaje técnico-jurídico y el uso frecuente de la remisión normativa.

En palabras de Martínez Sospedra, el lenguaje con que se escribe la Constitución, recurre a las técnicas siguientes:

1. El recurso a la técnica de la normación incompleta. Una característica llamativa del lenguaje constitucional es la frecuencia con la que a la hora de definir las normas constitucionales se recurre a la técnica de la normación in- 
completa. Dicho recurso implica, en primer lugar, que la Constitución establece una parte de la normación de una institución, materia o asunto, pero tan sólo una parte de la misma. En segundo lugar, que el texto constitucional llama al legislador ordinario a completar el programa normativo que el propio texto ha dejado incompleto, de tal modo que éste debe realizar su tarea marcado por aquella parte de la normación constitucionalmente fijada, que le viene impuesta por razón de la supremacía de la norma constitucional. En tercer lugar que, pese a ello, el legislador cuenta con un apreciable margen de maniobra, con una esfera de acción en el seno de la cual si bien la producción normativa viene vinculada parcialmente por la norma constitucional el Parlamento cuenta con un margen de acción, con una esfera de discrecionalidad importante, que lo es tanto más cuanto más incompleta sea la norma constitucional. En cuarto y último lugar que la Constitución renuncia a la aplicación inmediata y directa de su propia norma precisamente por razón de la voluntaria incomplitud, sustituyendo ésta por un mandato dirigido al legislador para que éste complete la normación constitucional ejerciendo una discrecionalidad reducida que, empero, permite una pluralidad de normaciones de desarrollo y concreción. De este modo la determinación concreta de la ordenación de materias, figuras, órganos o instituciones depende de la colaboración entre el Constituyente y el legislador ordinario, instrumentada mediante el deber de producción normativa que recae sobre este último y sobre el reparto del programa normativo efectivo por la Constitución. Como consecuencia la normación correspondiente se descompone en dos elementos: uno permanente, dotado de la supremacía propia de la ley fundamental, que se impone al Parlamento, otro complementario del anterior, variable con el tiempo, las opciones políticas de la mayoría parlamentaria y las necesidades del proceso político o el cambio social. La razón de ser del recurso a esta técnica, que permite combinar elementos permanentes y variables en una misma normativa, es doble: de un lado permitir una ampliación notable del campo de acción de pluralismo político, de las mayorías cambiantes, sin necesidad de establecer un núcleo normativo completo dotado de la estabilidad propia de la Constitución, del otro facilitar la adaptación de la ley fundamental a las cambiantes circunstancias políticas y sociales, sin perjuicio de un afirmar un núcleo normativo permanente...

2. El uso abundante de conceptos jurídicos indeterminados. Si bien el uso de conceptos jurídicos indeterminados no es per se una característica de la formación constitucional, no obstante sí lo es la abundancia e importancia de su uso en la ley fundamental. Aunque más destacada en unas partes de la Constitución que en otras... resulta llamativa la particular afición del Constituyente por esta técnica. La razón de ser de tal uso no es difícil de determinar, y está ligada a la vocación de permanencia de la ley fundamental. Como es 
bien sabido tales conceptos tienen como característica esencial el carecer de un significado preciso, aunque éste es concretizable por los operadores jurídicos y concretizable, en su caso, por jurisdicción.

Pues bien, en el lenguaje constitucional su abundante presencia se debe al hecho de que no se limitan a operar como cláusulas de cierre de la normativa concreta, como suele suceder en su uso en la legislación ordinaria, sino que, sin perjuicio de cumplir dicha función, establecen una normativa constitucional imprecisa pero determinable mediante el recurso a conceptos de orden jurídico, pero también sociológico, político, cultural, etcétera, que dota de flexibilidad a la formación constitucional, permite la evolución de la Constitución viva sin necesidad de recurrir a los costes y riesgos de la revisión constitucional y sin cesuras en la continuidad de la formación misma. De ahí su uso intensivo en aquellas partes de la Constitución de carácter acentuadamente doctrinal, más allá del uso tradicional de las cláusulas de cierre, que también se da.

Naturalmente ello no facilita la tarea de la interpretación constitucional, no es casual que sea en torno a tales conceptos donde se halle el punto nodal de la querella, tradicional en el constitucionalismo USA, entre los partidarios de la strict construction y quienes sostienen la actualización de la ley fundamental, entre otras cosas porque obliga a un recurso intensivo a técnicas peculiares de interpretación y tiende a acentuar la función práctica del recurso a los principios y orden de valores de la Constitución, pero, en contrapartida, su uso tiene ventajas evidentes. Desde luego el problema que el uso de tales conceptos plantea es creciente con el tiempo, pues obviamente recursos interpretativos de gran autoridad y certeza - como el recurso a los trabajos parlamentarios como medio de acreditación de la "voluntad del Constituyente" - ven su valor drásticamente disminuido con el transcurso del tiempo en cuanto al contenido de estas cláusulas se refiere...

3. El uso del lenguaje: preferencia por el no técnico. No hace falta comulgar con quienes ponen el acento en la función pedagógica de la Constitución, ni en quienes subrayan su utilidad a efectos de propaganda, para tomar nota del hecho de que las Constituciones tienden a emplear con frecuencia en sus textos el lenguaje ordinario, o, por decirlo de otro modo, que no emplean el lenguaje técnico-jurídico con la asiduidad con que lo emplea el legislador ordinario. Las razones de esta conducta son varias, y algunas de ellas deben resultar evidentes a la vista de lo que llevamos dicho. En efecto, la mayor relevancia del lenguaje no técnico implica, en primer lugar, el deseo de huir de una legislación diseñada para procurar una solución legal única, o, dicho en términos positivos, la voluntad de hacer posible una pluralidad de desarrollos legislativos posibles de las normas constitucionales concretas; en segundo lu- 
gar permite una mayor flexibilidad de la formación constitucional, al estar el lenguaje ordinario más abierto a la mutación del significado de sus términos que el técnico-jurídico; en tercer lugar habría que señalar que el uso del lenguaje ordinario hace más fácil la inteligencia de la Constitución por los legos en derecho y que, en consecuencia, facilita el control del cumplimiento de la misma y de sus desviaciones, tanto por los ciudadanos como por los medios de comunicación, amén de permitir una más fácil difusión de su conocimiento. De ahí la importancia que tiene la forma literaria en el cumplimiento de las funciones políticas que está llamada a desempeñar la Constitución.

A diferencia de lo que sucede con la técnica anterior la presente no ofrece especial cualificación en su uso por razón de la materia, el uso de expresiones ordinarias es común en todas las partes de la Constitución, si acaso señalar la particular relevancia del mismo en la formulación de las normas de principio, cuya importancia resulta obvia...

4. El uso abundante de las normas de principio y de la remisión normativa. Por último los textos constitucionales hacen un uso intenso de las normas de principio y de las remisiones normativas. La razón de ello es simple. Por lo que toca a las primeras las mismas tienen su espacio natural en la Constitución por razón del objeto de la misma. Si éste es el establecimiento de la estructura general del orden vinculante de convivencia, así como del sistema de ordenación general y de dirección de la sociedad (por eso es Constitución "política"), va de suyo que el tipo de normas que mejor se adapta a ese objeto es, precisamente, el de las normas de principio, en cuanto que éstas establecen ordenaciones muy generales, verdaderas "reglas de organización" del campo normativo al que se refiere... Por lo que toca a las segundas su uso frecuente en la ley fundamental se debe a razones a estas alturas obvias. El grado máximo de flexibilidad y capacidad de adaptación de la Constitución, y uno de los métodos que mejor se acomoda a su carácter de ordenación general es precisamente la remisión normativa. No obstante se hace necesario añadir que su notable aumento en las Constituciones democráticas se debe a otra razón, no necesariamente menos noble: la necesidad de negociación entre fuerzas políticas y sociales divergentes —e incluso antagónicas - para formular una Constitución democrática viable puede tropezar con el obstáculo de regulaciones sobre las cuales el consenso es momentáneamente imposible. La remisión normativa constituye entonces una técnica particularmente indicada a la hora de establecer lo que Schmitt denominó, no sin cierta ironía "compromisos dilatorios". 13 
Las técnicas reseñadas son propias de un texto que en el plano normativo-lingüístico y de significados está abierto, al igual que su techo ideológico, por lo que no es repudiable la plurisignificación o el empleo de términos que designen "compromisos dilatorios" o "apócrifos" (Schmitt); más bien la "lengua de la Constitución" es fruto de un pacto político que históricamente subyace a la Constitución de origen democrático; obligada a dar cabida como un gran paraguas a todas las visiones ideológico-culturales de una comunidad política. En este sentido las "cláusulas económicas y sociales" son un botón de muestra elocuente de la textura abierta de la Constitución y sus normas, ya que la Constitución contemporánea es un precipitado normativo de las tres tradiciones constitucionales e ideológicas de occidente. Constitucionalismo liberal, constitucionalismo democrático y constitucionalismo social.

\section{LAS “CLÁUSULAS ECONÓMICAS Y SOCIALES” COMO NORMAS CONSTITUCIONALES Y SU EFICACIA NORMATIVA U OPERATIVIDAD}

La recepción de las "cláusulas económicas y sociales" en las Constituciones, fruto del influjo del constitucionalismo social y democrático de entreguerras, vino a poner a prueba a la dogmática constitucional tradicional de cuño liberal y neoliberal, la que como hemos visto en caso de Chile devalúa estas cláusulas a través de tópicos o lugares comunes relativos a la transformación de la justicia social y el bienestar común en un catálogo de derechos justiciables (Zippelius), pero sin dar cuenta de un concepto normativo de Constitución y de la estructura normativa de ésta, datos básicos a la hora de determinar la eficacia u operatividad de estas cláusulas.

Resume esta posición teórica e ideológica neoliberal con agudeza el politólogo italiano G. Sartori:

Pero hablando en serio, las Constituciones son "formas" que estructuran y disciplinan los procesos de toma de decisiones de los Estados. Las Constituciones establecen la manera en que se crearán las normas; no deciden, ni deben decidir, qué debe ser establecido por las normas. Es decir, que las Constituciones son, ante todo, procedimientos cuya intención es la de asegurar un ejercicio controlado del poder. Por tanto, y por el contrario, el contenido de las Constituciones es y debe ser neutral. Una Constitución que se propone establecer políticas, es decir, de contenido político, desplaza a la voluntad po- 
pular y hace a un lado a las instituciones que toman las decisiones políticas (el Parlamento y los gobiernos), a los que se les reserva constitucionalmente el poder de decidir las políticas.

Debemos tener cuidado, entonces, con las "Constituciones en que se plasman aspiraciones". Así como hemos tenido, con resultados desastrosos, economías que se fijaban objetivos (el tipo soviético de economías centralmente planificadas), en la actualidad estamos propiciando las "Constituciones con objetivos", que muy probablemente resulten igual de desastrosas. Las "Constituciones con aspiraciones" son, a final de cuentas, una desviación y una sobrecarga de las capacidades constitucionales que resultan, finalmente, en su incapacidad de funcionar. Si los constituyentes no pueden resistir la tentación de enseñar toda la panoplia de sus nobles intenciones, deberían limitar éstas a un preámbulo "programático" de intenciones y de especificaciones. ${ }^{14}$ Sin embargo, de allí en adelante las constituyentes deberían dedicarse sin desviaciones a lo que seriamente se les pide que hagan, es decir, a establecer una estructura de gobierno que enfrente, entre otras cosas, la necesidad de gobernar.

La dogmática constitucional tradicional admite por principio este abordaje de la Constitución básicamente como instrumento de gobierno, porque permite devaluar una Constitución económica y social tributaria del constitucionalismo social y democrático, y al mismo tiempo reservar las garantías jurisdiccionales de la Constitución para su derecho objetivo y subjetivo. ${ }^{15}$ En este contexto le resulta natural a la dogmática tradicional neoliberal y neoconservadora sostener la "fuerza normativa" de la Constitución, en su contenido económico-social neoliberal e incluso incurrir sin esfuerzo en la patología del "fetichismo constitucional". Así se trasluce un doble discurso: plena eficacia normativa (horizontal y vertical) para los derechos civiles, en especial de contenido patrimonial, y

14 Nos recuerda el propio Sartori la distinción legal italiana entre normas "programáticas" e "imperativas". Las primeras, "norme programmatiche" son, por decirlo así, normas de tendencia, reglas que se deben aplicar sólo cuando - y en la medida en que - son aplicables. Únicamente las últimas, "norme precettive", son las que tienen toda la fuerza de obligaciones constitucionales. Así, se entiende que cuando la Constitución italiana afirma que, por ejemplo: "La República protege el paisaje", ésta es una norma programática que no autoriza a millones de italianos a demandar al Estado por millones de liras cuando descuida el paisaje.

15 En esta línea consistente se sitúa el concepto de Constitución y constitucionalismo que desarrolla G. Sartori como equilibrio —inestable y difícil— entre "el ejercicio del poder (gubernaculum) y el control sobre el poder (jurisdictio)”, p. 25. En Morán, M. L., Elementos de teoría política, Madrid, Alianza Editorial, 1992, pp. 13-25. 
ninguna eficacia normativa para cláusulas "económicas y sociales", condenadas por programáticas o irreales, cuando no perniciosas.

Se añade a este abordaje la condena de la "grafomanía" constitucional de los ciclos constitucionales más recientes de nuestra América Latina, que se inician en la década de 1980 y en especial el más reciente de la presente década (Venezuela, Ecuador y Bolivia), como una suerte de nuevo constitucionalismo y política constitucional "surrealista" y "populista", cuando no acusada de autoritaria o cesarista.

Críticamente cabe apuntar que las mentadas "cláusulas económicas y sociales" son parte integrante de la Constitución, que ésta no es un instrumento de gobierno neutral en lo ideológico, todo lo cual es obvio; y por ende lo que corresponde - si es consistente en el plano dogmáticoes situar estas cláusulas en la Constitución (parte dogmática u orgánica), identificando la norma constitucional como una norma de conducta o norma de organización (norma orgánica, sea "constitutiva" o "funcional", o norma programática, orientada a fines como servir de directrices a los poderes públicos o como reglas hermenéuticas para tales poderes, en especial para el Poder Judicial y el Tribunal Constitucional), fijar su alcance como regla de competencia (regla negativa o prohibitiva o positiva o afirmativa), su estructura normativa precisa y consiguientemente su eficacia normativa u operatividad.

Sobre esta particular estructura normativa constitucional y operatividad de las "cláusulas económicas y sociales", Vanossi es bastante esclarecedor al afirmar:

Pero, en definitiva, las cláusulas económicas y sociales, como todas las normas constitucionales de cualquier tipo y clase, cumplen el rol de normas de competencia, ya que están señalando afirmativa o negativamente, positiva o prohibitivamente, la órbita de la esfera estatal y la órbita o el ámbito de la libertad personal. Son razones históricas y cuestiones de técnica constitucional las que motivan que en unos casos se acuda a la redacción "positiva" y en otros se haga uso de la forma "negativa". Esto es así, con prescindencia de quién sea el demandable, que tratándose de las cláusulas económicas y sociales, en unos casos puede serlo el Estado, en otros los particulares o, a veces, ningún sujeto en concreto (cláusulas innocuas). Esto último es lo que ocurre cuando dichas cláusulas son "directivas" a los poderes políticos: en el actual reparto de competencias, el Poder Constituyente utiliza la técnica de las cláusulas programáticas-directivas con el objeto de imponer funciones a ciertos 
órganos, mas con la singularidad de que esos deberes estatales se cumplen y se exigen puramente en el terreno de la responsabilidad política.

La operatividad no es una cualidad propia de los derechos individuales e impropia de los derechos sociales. La determinación de la operatividad es una cuestión de hecho, a dilucidar por la autoridad de aplicación en cada caso y, en definitiva, por los jueces. Así, por ejemplo, en el artículo 14 bis hay normas operativas y hay normas no-operativas: en los casos del derecho de huelga y de la protección al igual salario, no hacen falta nuevos órganos, y en cuanto a los procedimientos los puede suplir el juez dentro de la órbita de su jurisdicción, en cambio, parece claro que cláusulas tales como las referentes a la vivienda familiar y al establecimiento del seguro social no son operativas, desde el momento que para su aplicación hace falta crear nuevos órganos y procedimientos.

No creemos que "operatividad" sea sinónimo de no-programático; ni que lo programático sea necesariamente lo equivalente a no-operativo. Desde el momento que las cláusulas programáticas también están dirigidas a los jueces (reglas de interpretación) y éstos las incorporan a su selección axiológica, resulta que tales cláusulas tienen una aptitud aplicativa inmediata.

La principal función de las cláusulas programáticas consistirá en evitar que en la aplicación de la Constitución sus intérpretes le asignen un sentido reñido con los valores y los fines consagrados más reciente o contemporáneamente en la norma suprema o que simplemente la comunidad ha vivenciado como prioritarios. En definitiva: que el intérprete no pueda regresar al ámbito prexistente y deba estar inmerso en los objetivos de hoy y de aquí. ${ }^{16}$

De lo expuesto, probablemente el quid de la cuestión de la operatividad de las "cláusulas económicas y sociales" esté en la justiciabilidad de los derechos sociales; cuestión que como hemos dicho en otro lugar está dominada por un "lecho de Procusto" que somete conceptualmente a estos derechos al molde de los derechos subjetivos, que poseen una configuración precisa derecho-deber (sujetos, contenido relacional: facultas agendi, facultas omittendi y facultas exigendi, obligaciones, etcétera) y que es compatible con la tutela reintegrativa del derecho, esquema de filiación privatista, que penetró incluso la clásica doctrina de los derechos subjetivos públicos. Una respuesta dogmática que pretende explicar estos derechos sociales zafando del corsé tradicional, es la dada en el constitu-

16 Vanossi, J. R., op. cit., nota 2, pp. 373 y 374. Dando un enfoque distinto pero coincidente Bidart Campos, Germán J., Teoría general de los derechos humanos, México, UNAM, Instituto de Investigaciones Jurídicas, 1993, pp. 413 y 414. 
cionalismo latinoamericano por Bidart Campos al designarlos como derechos por "analogado" en la que es característica una obligación "activamente universal" del sujeto pasivo Estado frente a los individuos que componen la sociedad, y que la cumple no dando o haciendo algo (prestaciones) en una relación de alteridad personalizada en cada carenciado, sino haciendo o dando algo "impersonalmente al conjunto social", en el marco de la prosecución del bien común, concibiendo y ejecutando políticas públicas de bienestar, sea directamente a través de su administración o indirectamente con la colaboración de la sociedad civil o imponiendo cargas a ésta.

En palabras de Bidart Campos estos derechos por "analogado", explican o se proponen explicar conceptualmente los derechos sociales que propiamente son derechos prestacionales, admitiendo derechos sociales que escapan a la matriz prestacional:

Lo de derechos "por analogado" quiere decir dos cosas fundamentales: a) que estamos frente a "derechos", o sea, a una entidad propiamente jurídica; b) que estos derechos no son iguales, sino solamente semejantes, a los derechos que traban una relación intersubjetiva directa entre su titular y un sujeto pasivo concreto que, frente a él, tiene un débito también determinado, sea de abstención, sea de dar o de hacer.

¿Dónde radica la diferencia que nos hace hablar de "analogado" y no de "igualdad" entre unos derechos y otros?

En que los derechos por analogado, con ser titularizados por un sujeto activo, y con tener en reciprocidad al Estado como sujeto pasivo, no concretan individualmente una obligación prestacional del Estado frente a cada titular de esos derechos, sino una obligación estatal que apodamos "activamente universal".

Estas dos palabras requieren su explicación: "activamente" es un adverbio que alude a una obligación que no es negativa (de abstención u omisión) sino positivamente prestacional (de dar o de hacer); "universal" significa que esa obligación activa existe frente a todo el conjunto de titulares de los derechos por analogado, y no frente a cada uno en particular, razón por la cual "cada uno" carece de relación intersubjetiva con el Estado, y comparte una relación colectiva o plural de "todos" con él.

"Frente a todos" existe la obligación activamente universal del Estado, pero no "frente a cada titular individual". Esto explica, del mejor modo como en su momento pudimos hacerlo, el porqué no llegamos a descubrir la exigi- 
bilidad personalizada en "cada uno" para impeler al Estado a cumplir como sujeto pasivo "frente a todos" su obligación "activamente universal". ${ }^{17}$

Concluido estos pasos, podemos fijar los términos de la discusión, a saber: desarrollo infraconstitucional y en especial legislativo de estas cláusulas económicas y sociales y justiciabilidad de las cláusulas referidas a derechos económicos, sociales y culturales. Y en este campo nuestra América Latina es pródiga en la justiciabilidad de derechos sociales y en el desarrollo jurisprudencial en sede de amparo ordinario e inclusive extraordinario como ocurre con la tutela en Colombia, pero al mismo tiempo pone en evidencia las dificultades de instalar un Estado social o benefactor en economías subdesarrolladas o en vías de desarrollo; de suerte que tal justiciabilidad puede dar origen a verdaderas patologías de judicialización de políticas públicas y quebrantos al sistema de derechos.

El origen del problema estriba en que la cobertura de necesidades colectivas a través de una red de protección social sostenida por el Estado exige una ordenación de la economía y de la sociedad bajo un signo programático o ideológico distributivo y redistributivo, que adopta la forma de normas y directivas económico-sociales (políticas públicas) en las que la centralidad del gobierno y la injerencia del Congreso Nacional se dan en las coordenadas del proceso político democrático.

\section{CONCLUSIONES: DE LA JUSTICIABILIDAD DE LOS DERECHOS ECONÓMICOS, SOCIALES Y CULTURALES A LA OPERATIVIDAD DE LAS NORMAS CONSTITUCIONALES}

En otros lugares y momentos he abordado la debatida cuestión de la justiciabilidad de los derechos económicos, sociales y culturales, y el análisis de la jurisprudencia constitucional, y como es obligado hemos hecho una crítica dura a las posiciones dogmáticas tradicionales. Al mismo tiempo hemos sostenido que la crítica a los derechos sociales, se construye desde un "lecho de Procusto" que utiliza el molde o corsé de los derechos subjetivos y su tutela judicial, "lecho" que es una trampa ideológica, que bajo el pretexto de la problemática cuestión de la justiciabilidad, lo que hace es ocultar dos extremos básicos: primero, los de-

17 Bidart Campos, Germán J., El derecho de la Constitución y su fuerza normativa, Buenos Aires, EDIAR, 2004, pp. 235 y 236. 
rechos económicos, sociales y culturales, no son una categoría homogénea explicada con base en los derechos prestacionales o de crédito en que los sujetos son Estado e individuos carenciados, sino por el contrario una categoría heterogénea; y segundo, la justiciabilidad de estos derechos no agota la operatividad o eficacia vertical y horizontal de éstos frente a los poderes públicos. Indica Bidart Campos:

Todo arranca de la también difícil tarea de unificar a todos los derechos sociales en una modalidad única, cuando en verdad presentan una copiosa diversidad, sin perjuicio de que todos los tipos de su trama sean indivisibles e indisociables.

En general, estamos habituados a visualizar los derechos sociales como "derechos prestación" o derechos de prestación y es cierto que el débito positivo de dar o de hacer suele predominar en los derechos sociales y ser señalado como una característica que los diferencia de los clásicos derechos civiles, a los que el sujeto pasivo satisface normalmente con un deber de omisión o abstención (no violarlos, no interferirlos, no impedir su ejercicio).

Exhiben: a) a veces un aspecto de libertades (de asociación sindical, de huelga); b) otras, obligan a prestaciones variadas: un bien (como la vivienda); un servicio (como la educación o la sanidad); c) en algunos casos, suponen transferencia de un monto económico (como en las pensiones o en los subsidios); d) no faltan las transferencias compensatorias (en las pensiones de viudez, o en la protección a discapacitados, o en el subsidio de desempleo); e) se mencionan asimismo algunos bienes, como el medio ambiente limpio o la calidad de vida. Dejamos para el final un último ejemplo de derechos a ciertas posiciones o status legales — según Laporta- que aparece en el derecho "al" trabajo, y que admite cuatro sentidos: como libertad de ejercer una actividad laboral; como referencia al derecho derivado de una relación laboral ya establecida (salario digno, condiciones de protección - entre otras, a no ser rescindida sin causa-); como derecho a un subsidio en caso de falta eventual de trabajo; y como derecho a acceder a un puesto de trabajo. ${ }^{18}$

En este lugar, el propósito es más modesto, consiste en aproximarnos desde un concepto normativo de Constitución y distinguir tipológicamente sus normas y estructura, para a partir de allí fijar los alcances de su eficacia u operatividad, contribuyendo de este modo a desvelar los tópicos o lugares comunes, fruto de un cuño o prisma ideológico y de inconfensables intereses. 
En cuanto a la Constitución económica y a los derechos sociales como lo dijimos hemos realizado una lectura crítica. ${ }^{19}$ Complementaria a esta lectura, es este trabajo que propone modelar la eficacia normativa u operatividad de las "cláusulas económicas y sociales" desde un concepto normativo de Constitución, tipología de normas constitucionales y estructura normativa de ésta, y una vez desechada una aproximación dogmática tradicional y también una perspectiva quejada de "fetichismo constitucional", nos permite concluir que toda la Constitución requiere de desarrollo infraconstitucional, y por ende de una política institucionalizada desplegada para su plena eficacia normativa. Ello toca en especial a las normas constitucionales que denominamos con Vanossi "cláusulas económicas y sociales", pero no se trata de un desarrollo infraconstitucional por los poderes públicos enteramente libre, sino que se trata de un desarrollo en que existe una predeterminación material de la Constitución, pues las normas de principio condensan valores y principios constitucionales, y en esa medida se produce que la norma constitucional (norma de conducta y norma de organización) — regla de competenciatenga una eficacia positiva o negativa, y a la custodia de esta operatividad se han estatuido garantías sociales, políticas y jurídicas, en especial jurisdiccionales. Tales normas de principio son un precipitado normativo de ideologías que conforman un techo ideológico o fórmula política que es axial en la hermenéutica constitucional.

En este punto a nuestro juicio está la clave de una democracia constitucional y su legitimidad, y que es la apertura de su techo ideológico, condensando los aportes asimétricos del constitucionalismo liberal, democrático y social, y desde esta perspectiva se observa un severo déficit en nuestra Constitución, por su origen otorgado, autoritario y neoliberal, no completamente purgado por el ciclo de reformas de primera genera-

19 Zúñiga Urbina, Francisco, “Constitución económica y Estado empresario”, Revista de Derecho Público, Facultad de Derecho de la Universidad de Chile, núm. 67, 2004; id., "Derechos económicos, sociales y culturales: apuntes acerca de la naturaleza y justiciabilidad de los derechos fundamentales", Revista Pensamiento Constitucional, año XIII, núm. 13, P. Universidad Católica de Lima, 2008, pp. 329-356, y Revista de Derecho del Consejo de Defensa del Estado, Santiago, 2008. También "Acerca de la compatibilidad de la Constitución económica con el sistema político en Europa", en Mezzetti, Luca (coord.), Costituzione economica e libertà di concorrenza. Modelli a confronto, Turín, Giappichelli Editore, 1994. 
ción (1989-2005). Se trata de lograr un punto medio entre dos opuestos: la Constitución neutral y la Constitución dirigente.

Asimismo, el concepto normativo de la Constitución nos lleva a reconocer en ella una norma peculiar o especial, un subsistema de normas conformadoras de un "orden fundamental", "marco general" o "abanico de posibilidades", lo que traslada el centro de gravedad al desarrollo infraconstitucional de la Constitución por los poderes públicos, y tratándose de las "cláusulas económicas y sociales", sean normas de organización (orgánicas o programáticas) dirigidas al Estado (la economía y la sociedad en sus relaciones con el poder estatal) o normas de conducta (derechos económicos, sociales y culturales y sus garantías), operarán como reglas de competencia positiva o afirmativa, y por ende con una especial fuerza rectora de la actividad que el Estado despliega o la empresa, y tal fuerza rectora se orienta a tales poderes públicos, impidiendo la regresividad de políticas públicas relativas a bienes y servicios públicos que el Estado debe prestar, es decir, debe haber políticas públicas y servicios-bienes públicos apropiados para la "procura existencial" o cobertura de las necesidades asociadas a estos derechos. ${ }^{20}$ Entre los poderes públicos concernidos directa y especialmente por las "cláusulas económicas y sociales" están el gobierno y la administración del Estado, dedicados constitucionalmente al desarrollo; ya que de su actividad depende el montaje efectivo de una Estado social o benefactor, y sólo esta forma de Estado con roles determinados en la economía y sociedad civil puede conjurar los peligros de activismo y judicialización de las políticas públicas cuando son justiciables los derechos sociales, y la eventual quiebra del "sistema de derechos".

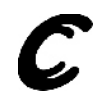

20 Pérez Luño, Antonio Enrique, Derechos humanos. Estado de derecho y Constitución, Madrid, Tecnos, 1984, pp. 225 y ss. También Ruiz-Rico, Gerardo, Fundamentos sociales y políticos de los derechos sociales en la Constitución Española, Madrid, Centro de Estudios Constitucionales, 1990. 